\title{
Research on the Construction and Value of Island Park in Zhoushan City
}

\author{
Longwei Liu, Chenlin Bi, Kai Xun, Xu Guo \\ School of Economics and Management, Zhejiang Ocean University, Zhoushan, Zhejiang, 316022
}

\begin{abstract}
The establishment of a natural reserve system with national parks as the main body is a major measure to implement Xi Jinping's thoughts on ecological civilization and a major reform task proposed by the 19th National Congress of the Communist Party of China. Natural reserves are the core carrier of ecological construction, the precious wealth of the Chinese nation, and an important symbol of beautiful China. They play a primary role in maintaining national ecological security. [1] Aiming at the national construction of the Sanjiangyuan and Qianjiangyuan Forest Reserve and other national parks, the Zhejiang government based on the province's resource conditions and location advantages, made plans to build marine parks, with a view to building island parks with their own characteristics in Zhoushan. On the one hand, the establishment of island parks can create a good protection condition for the local ecological environment to maximize the protection of our cherished marine biological resources and biological resources on the island. On the other hand, the establishment of island parks also contributes to the cultural exchange and spread of Zhoushan, Zhejiang. Can play a great role in promoting.
\end{abstract}

Keywords: Island park, Ecosystem, Laws and regulations.

\section{The Concept, Definition and Characteristics of Island Parks}

\subsection{Concept and Definition}

National parks According to the definition of the International Union for Conservation of Nature (IUCN), national parks refer to natural land or oceans mainly used for ecosystem protection and recreational activities. They are designated to: protect the integrity of one or more ecosystems for present and future generations Sex; Excluding any form of development and possession behavior that is detrimental to the management purpose of the protected area; Provide a base for spiritual, scientific, educational, entertainment and sightseeing for the public, and a protected area for ecosystem protection and recreational activities. The main management objectives of national parks determined by the World Conservation Union are: to protect natural and cultural resources of national and international significance; to ensure the ecological stability and diversity of representative and typical geographic areas, and to make the biological populations The continuous development of species and genetic resources; Provide spiritual, educational, cultural and recreational opportunities for tourists while maintaining the natural state as much as possible; Eliminate and prevent all development and possession behaviors that are contrary to the purpose of establishing a national park; While not violating other management goals, fully consider the needs of local communities. [1] This article believes that island parks are marine island parks derived from the framework of national parks. They focus on protecting the offshore marine environment and maintaining marine biological resources in my country, and are the places for nature education to be marine parks.

\subsection{Features}

1) It is a branch under the framework of national parks. The main purpose is to protect the marine environment, maintain and repair the island environment, protect marine fish resources, and minimize the interference and impact of human activities on the environment.

2) Adhering to the principle of protecting the environment as the primary theme, the primary purpose of establishing and setting up island parks is to protect the marine and island resources and the environment rather than large-scale development, with the purpose of seeking profit.

3) At the same time as the island park is established, it is necessary to have complete protection and development supporting laws, regulations, and special supervision and enforcement departments to avoid unclear legal provisions, unclear powers and responsibilities, and unclear assignment of responsibilities that lead to inferior development. Protection is inferior to the occurrence of unprotected situations.

4) Leading by the national department, it is mainly responsible for the development and evaluation of island resources and the protection and maintenance of the ecological environment, and the establishment of a special market department to develop targeted commercial profit service activities.

\section{The Function and Value of Island Park}

\subsection{Features}

The marine park has the function of protecting and inheriting the natural environment, protecting the marine fishery resources, publicity and education, nature education, and sightseeing.

1) Protection and inheritance of natural functions: Zhoushan Island has an unrepeatable geographical location advantage. Zhoushan City is located on the southeast coast of China. It is the only provincial prefecture-level city composed of archipelagos in the country. The entire city of Zhoushan is composed of 1,390 islands. The total area is 22,200 square kilometers, and the biodiversity is relatively rich. There are 
517 species of 97 families and 311 genera of vascular plants in wetlands, including 4 national class II protected plants, including Zoysia sinensis, wild soybean, wild buckwheat, coral vegetable One species of rare and endangered plant at the provincial level in Zhejiang Province is seaside hibiscus. Among them, Zoysia chinensis and coralline are distributed in Putuo, and wild soybean, wild buckwheat and seaside hibiscus are distributed throughout the district. [2] Protecting the diversity of biological populations, maintaining the island's ecological environment, and enabling the island's environment to achieve sustainable development is the fundamental purpose of the establishment of the marine park.

2) Function of protecting marine fishery resources: As the third fishing ground in the country, Zhoushan is rich in marine fishery resources. However, due to people's large-scale fishing in recent years and the increase of people's consumption demand, fishery resources are nearly exhausted, and wild fishery resources are also affected. The great impact is that it has broken the original ecological balance and established island parks, which is conducive to protecting the island's offshore environment and marine fishery resources.

3) Publicity and education function: This is the core function of the island park. The marine environment, biological resources and fish resources of the island park are the most direct and practical experience in people's experience. This is for the country to promote the protection of the ocean, the island environment, and the protection The diversity of biological resources has intuitive practical significance.

4) Nature education function: The nature education function is of great significance to the growth of children and adolescents. A good external ecological environment is an important realistic carrier for the development of nature education, allowing children and adolescents to learn natural things, phenomena and Cognition, so that children and young people will form an awareness of caring for nature and protecting the ecological environment from an early age.

5) Tour and visit function: The tour and visit function is the manifestation of the value of the establishment of the island park. The establishment of the island park can provide a new place for the daily leisure and entertainment needs of local residents, so that people can better go in the process of becoming close. Relax your body and mind, on the other hand, you can also experience a good island natural environment experience for foreign tourists.

\subsection{Value}

The value function of island parks can be divided into: scientific research value, environmental value, cultural value, economic value and leisure value.

1) Scientific research value: the establishment of island parks can protect nature and the environment, and can maintain biological diversity. This has significant scientific research value for my country's biological and ecological environment, and is useful for studying the protection and development of island biological resources in my country. It has far-reaching research significance and is of reference significance for exploring the ecological protection methods and methods of other islands.

2) Environmental value: the establishment of island parks, from a small perspective, the island park can maintain the natural and ecological environment around the island and reduce the damage to the offshore environment caused by man-made fishing. From a macro perspective, the establishment of island parks has far-reaching significance for the birds and fish resources in the surrounding waters.

3) Cultural value: The natural landscape and man-made landscape included in the establishment of the island park have a perfect and cultural influence on the inheritance, development and promotion of the fishing culture, and it also reflects the comprehensive thinking of the current fishermen.

4) Economic value: The establishment of island parks can bring additional economic income to local fishermen and change the thinking and concepts of local fishermen. Green water and green mountains are the golden mountains and silver mountains. A good natural environment is the greatest wealth left to future generations, an inexhaustible source of wealth. At the same time, the island park can also inject a new impetus into the tourism resources of Zhoushan's tourism industry. The original ecological island environment is the tourism pursuit of contemporary people.

5) Leisure value: With the acceleration of modern life and urbanization, people have a great demand for natural scenery. The original ecological scenery of the beautiful island can make people get closer to nature, relax and eliminate the city. The irritability and pressure brought by the rhythm.

\section{Development Path of Island Park}

\subsection{Based on the Premise of Natural Protection, Moderate Development}

Island development should be based on the premise of nature protection, using the existing natural resources on the island, focusing on plants and the ocean, gradually increasing and planning the island's existing forest vegetation, and planting and cultivating fourth-level plants on islands with land conditions to make the islands Get rid of the deserted scenery of the mountains as soon as autumn is over. Strengthen island plant planting and cultivation planning, use plants to create characteristic natural scenery, and highlight the island characteristics of island parks. At the same time, make full use of plant resources, establish conservation and exhibition halls for cherished plant resources, and conduct a full-scale experiential tour that promotes environmental protection and increases knowledge.

\subsection{Integrate Geographical Location Resources}

In terms of site selection, the establishment of Zhoushan Island Park must avoid several larger islands, such as the two larger islands of Dongji and Shengsi, because the Dongji and Shengsi islands have been excessively developed by humans and cannot be better. It reflects the original ecological environment of the island park. On the other hand, Dongji and Shengsi Island have become well-known islands for 
people's island tourism. The development of other islands and the integration of several small islands together can allow people to experience the unique island scenery, and at the same time, it can also help the locals. Fishermen provide a good employment incentive, so that local fishermen can better understand the country's development policies.

\subsection{State-led, Multi-sector Collaborative Governance}

The project construction of island parks should be led by the state. The local government fully recognizes the ecological and scientific value of building island parks, and minimizes the impact of human activities on the natural environment without destroying the ecological environment. Expand the landscape diversity of the island park at different levels. Establish a special island ecological protection department and an ecological evaluation system, improve the laws and regulations on island ecological protection, and avoid environmental hazards that development is not as good as no development. Relevant departments are responsible for tourism activities, and the powers and responsibilities are the same. All renovations such as buildings should be approved by government departments. Establish cooperation with local universities, actively promote and set up island park development research and management committees, organically integrate ecological protection with science and scientific research, and promote better development of island parks. Strengthen the behavioral constraints of residents and tourists, formulate relevant laws, regulations and supervision policies, so that what people come to leave behind are only memories, and what they take away are good memories, and reduce the impact of human activities on the ecological environment.

\subsection{Strengthen the Excavation of Island Fishing Culture}

Fishing culture is the soul of island park construction and the experience of residents and tourists. Fishing culture should be implemented in the planning and construction of island parks, the research and inheritance of fishing culture should be strengthened, and the fishing culture characteristics of Zhoushan islands should be fully explored, and the island park should be built into one The unique island park that has the organic integration of Zhoushan's local fishing culture and the island's ecological environment, strengthens the integration of culture and tourism, appropriately creates cultural tourism industry business cards on the island, and designs ecological, convenient and diversified cultural tourism experience projects, To maximize the cultural value of the island.

\subsection{Maintain the Ecological Image of the Park, Attach Importance to the Experience of Tourists, and Prevent Environmental Pollution}

During the development of the island park, it is necessary to eliminate the environmental pollution caused by man-made development and construction. During the construction, the impact of man-made activities on the environment should be reduced as much as possible. The relevant departments shall establish construction rules and regulations to prevent environmental pollution and damage caused by construction activities. The image of a good ecological environment in the park reduces the on-site experience of tourists. For tourists who come to the island to formulate tour rules, reduce the substitution of tourists' non-essential supplies, prevent the substitution of some toxic substances, and set up designated garbage collection points for sorting and recycling. Advocate and strengthen tourists to use biodegradable materials to reduce damage to the local environment. Strengthen the laws and regulations of offshore fisheries, protect the ecological balance of offshore fishery resources, and increase the offshore aquaculture and circular economy of characteristic fishery resources. With a view to turning the island park into a distinctive green island landscape.

\section{Conclusion}

Island parks are of great significance to our country's ecological environment protection and the maintenance of biological and plant diversity. At the same time, the development of green original ecological tourism can also promote the local economy and promote the guidance and development of island residents' awareness of environmental protection. In far-reaching significance, a good ecological environment is not only the precious wealth of our generation, but also the precious wealth to be passed on to the future. Whether or not to establish a national park or an island park, maintaining the ecological environment is not only a responsibility but also a matter for us. The obligation of all. Only when we protect our environment can the future environment give us better ecological feedback.

\section{References}

[1] Xinhua News Agency. The General Office of the State Council of the Central Committee of the Communist Party of China issued the "Guiding Opinions on Establishing a Natural Reserve System with National Parks as the Main Body" http://www.gov.cn/gongbao/ content/2019/content_5407657.htm

[2] Yuan Xinchang, Zhang Xiaomian, Chen Bin, Liu Bowen, Yu Lingjing, He Weizhong, Yue Chunlei, Gao Dahai, Lu Zhuan. Investigation of Plant Resources in Zhoushan Islands Wetland[J]. Zhejiang Forestry Science and Technology. 2015, 35(06): 63-67.

[3] Ouyang Zhiyun, $\mathrm{Xu}$ Weihua, Zang Zhenhua. Suggestions on Improving the Management System of National Parks[J]. Biodiversity, 2021, 29(03): 272-274.

[4] Yang Rui.China National Park Governance System: Principles, Goals and Paths[J]. Biodiversity, 2021, 29(03): 269-271.

[5] Yuan Xinchang, Zhang Xiaomian, Chen Bin, Liu Bowen, Yu Lingjing, He Weizhong, Yue Chunlei, Gao Dahai, Lu Zhuan. Investigation of Plant Resources in Zhoushan Islands Wetland[J]. Zhejiang Forestry Science and Technology, 2015, 35(06): 63-67.

\section{Author Profile}

Longwei Liu, Graduate student of School of Economics and Management, Zhejiang Ocean University. Research direction Agricultural and rural development.

Xu Guo, Master tutor of Zhejiang Ocean University, Research Direction: island tourism. 